\title{
Block Approach to the Simulation of Circulation and Tides in the Black Sea
}

\author{
S.F. Dotsenko ${ }^{1}$, V.B. Zalesny ${ }^{2}$, N.K.V. Sannikova ${ }^{1}$ \\ ${ }^{1}$ Marine Hydrophysical Institute, Russian Academy of Sciences, Sevastopol, Russian Federation \\ e-mail: sf_dotsenko@mail.ru \\ ${ }^{2}$ Institute of Numerical Mathematics, Russian Academy of Sciences, Moscow, Russian Federation \\ e-mail: vzalesny@yandex.ru
}

\begin{abstract}
The article gives the analysis of tidal parameters in the Black Sea with the field data for a variety of marine coastal areas. The characteristics of the basic parameters of tidal oscillations in the region and the examples of cotidal maps and maps of the lines of equal amplitudes for the semi-diurnal tide are presented. Besides, the Black Sea water circulation is simulated using the block approach. The $\sigma$-model of the ocean circulation developed in the Institute of Numerical Mathematics of RAS is applied. The model spatial resolution over the longitude and latitude is about $4 \mathrm{~km}$. 40 irregularly distributed $\sigma$-levels are preset over the vertical; the step in time is $300 \mathrm{~s}$. The vortex structure is distinctly manifested in the Black Sea circulation. The Rim Current which characterizes general cyclonic circulation along the Black Sea perimeter forming two evident vortices is reproduced. In general, results of numerical modeling in seemed like a good match observational data, as well as the results of other models of the Black Sea. To describe generation of tides, the module corresponding to the Sun and Moon tide-generating potentials is introduced into the $\sigma$-model. The analysis showed that the tides in the Black Sea are weakly expressed because of the relative smallness of the pool area. As the Black Sea straits are shallow and relatively narrow, so that does not contribute to the development of tides.
\end{abstract}

Keywords: the Black Sea, general circulation, tides, mathematical model, block approach, computational experiments.

DOI: $10.22449 / 1573-160 X-2016-1-3-19$

(c) 2016, S.F. Dotsenko, V.B. Zalesny, N.K.V. Sannikova

(C) 2016, Physical Oceanography

Introduction. Tidal height in the open ocean is an average of $1.2 \mathrm{~m}$. The appearance of the tides is due to the attraction of the Moon (and to a lesser extent of the Sun), acting on the rotating Earth. The tide-force acts on the entire surface of the earth (including land). The tides on the coasts of oceans and seas are the most noticeable.

The highest tides occur in North America in the Bay of Fundy and partly along the coast of Maine (USA). The maximum height of the tide measured here was $18 \mathrm{~m}$. The highest tide off the coast of the Russian Federation of $14 \mathrm{~m}$ height was registered in Penzhin Bay of the Sea of Okhotsk.

Characteristics of the Black Sea tides are generally based on the mareographic measurement data analysis reflecting the level fluctuations at different points of the sea coast, particularly in the major ports such as Odessa, Sevastopol, Poti, Constance, Samsun, Trabzon and others. Analysis of these data showed that the amplitude of the tidal oscillations of the Black Sea surface is less than $17 \mathrm{~cm}$ : in the central parts of the western and eastern parts of the coast it is $9 \mathrm{~cm}$, off the Crimean coast $-2-3 \mathrm{~cm}$. Thus, the tides in the Black sea are relatively weak, and that's the reason they are not studied enough. 
Currently, the effective numerical models for calculation of the tides in barred and semi-bounded sea basins have been developed [1 - 3]. There the finitedifference algorithms for rectangular and curvilinear nets with the field data assimilation are applied. These models are widely used in the calculation of tides in the complex geometry of the basins, in straits and other water bodies.

Overall characteristics of the Black Sea tides. The Black Sea is an inland sea of the Atlantic Ocean. The Bosporus connects it to the Sea of Marmara, through the Dardanelles it is connected with the Aegean and Mediterranean Seas, and through the Kerch Strait - with the Azov Sea. The Mediterranean tides are attenuated in the straits. Periods of the Black Sea seiches and tides are different, so the resonant modes in the Black and Azov Seas are impossible [4-10].

The parameters of the Black Sea tides are set according to the mareographs that monitor the level fluctuations at different points of the Black Sea coast, particularly in the major ports [4]. The analysis showed that the tides in the Black Sea are mild because of the relative smallness of the basin area. The Black Sea straits are shallow and relatively narrow, that doesn't contribute to the development of the tides.

According to the measurements, the average period of the tides in the Black Sea is about half a day. As it has already been mentioned, the tides in the Black Sea are a relatively weak wave phenomenon, the amplitude of the Black Sea level tidal oscillations does not exceed $17 \mathrm{~cm}$. The spatial structure of the semi-diurnal tide in the Black Sea is shown in Fig. 1.

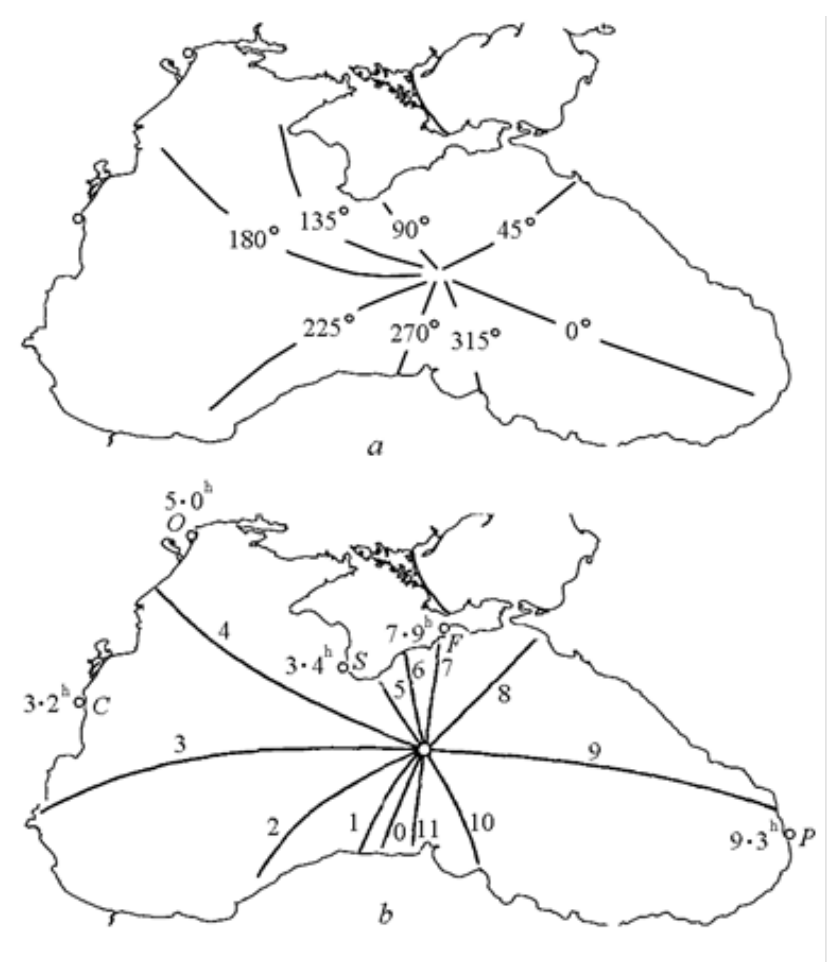

Fig. 1. Semi-diurnal tide in the Black Sea [11, 12]: $a$-cotidal map; $b$-map of isoamplitudes 
The values of harmonic constants of the main tidal harmonics (the average amplitude $H$ and the wave position angle $\gamma$ ) for the three Black Sea ports are given in the table $[11,13]$.

The values of harmonic constants of the Black Sea tides $(H-$ in $\mathrm{cm}, \gamma$ - in degrees)

\begin{tabular}{ll|c|c|c|c|c|c|c|c|c|c}
\hline Port & & $M_{2}$ & $S_{2}$ & $N_{2}$ & $K_{2}$ & $K_{1}$ & $P_{1}$ & $O_{1}$ & $\begin{array}{c}\text { Neap tide } \\
\text { average } \\
\text { amplitude } \\
(\mathrm{cm})\end{array}$ & $\begin{array}{c}\text { Syzygial tide } \\
\text { average } \\
\text { amplitude } \\
(\mathrm{cm})\end{array}$ & $\frac{H_{K_{1}}+H_{O_{1}}}{H_{M_{2}}+H_{S_{2}}}$ \\
\hline \multirow{2}{*}{ Odessa } & $H$ & 3.5 & 1.9 & 0.5 & 0.8 & 0.9 & 0.6 & 0.4 & 10.8 & 3.2 & 0.24 \\
& $\gamma$ & 142 & 148 & 136 & 155 & 79 & 109 & 112 & & & 0.57 \\
Sevas- & $H$ & 0.4 & 0.3 & 0.1 & 0.1 & 0.3 & 0.4 & 0.1 & 1.4 & 0.2 & \\
topol & $\gamma$ & 110 & 90 & 126 & 100 & 79 & 23 & 61 & & & 0.58 \\
\multirow{2}{*}{ Poti } & $H$ & 2.9 & 1.2 & 0.7 & 0.5 & 1.5 & 0.35 & 0.9 & & \\
\hline
\end{tabular}

Ratio of the amplitudes of the diurnal and semi-diurnal harmonic components $\left(H_{K_{1}}+H_{O_{1}}\right) /\left(H_{M_{2}}+H_{S_{2}}\right)$ permits to determine the nature of the tides. So, for Odessa, they are semidiurnal as $\left(H_{K_{1}}+H_{O_{1}}\right) /\left(H_{M_{2}}+H_{S_{2}}\right)<0.25$, for Sevastopol and Poti $0.5<\left(H_{K_{1}}+H_{O_{1}}\right) /\left(H_{M_{2}}+H_{S_{2}}\right)<1.5$, and that is why the tides are mixed, irregular semidiurnal in these points [14]. In general, the average period of the Black Sea tides is 15 hours 25 minutes (Fig. 2) [15].

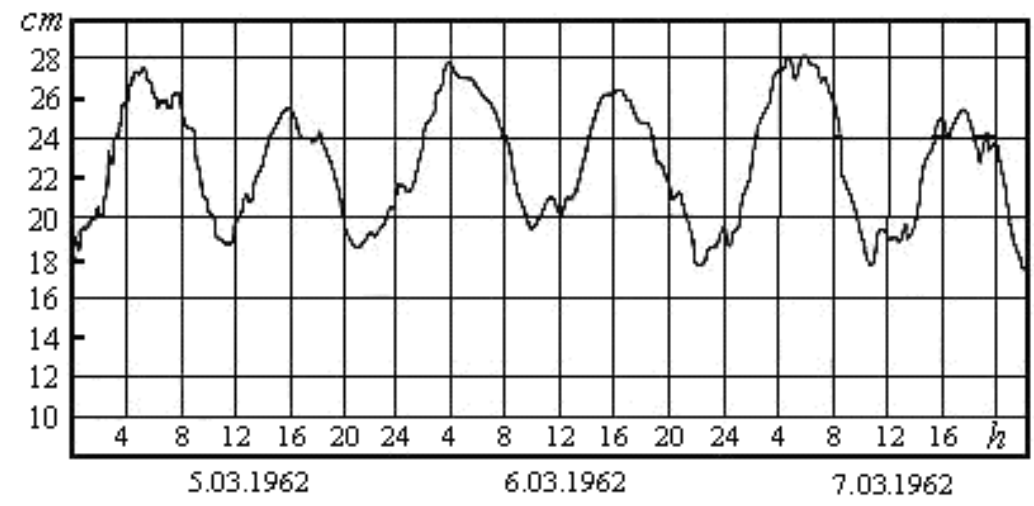

Fig. 2. The tide in the port of Constanta (March 5 - 7, 1962, full moon) [15]

The modern methods of the mathematical forecast of circulation. Below we are to describe briefly the $\sigma$-model for thermohydrodynamics proposed by the Institute of Numerical Mathematics of RAS (INM) and applicable to describe both the tides and water circulation in the barred basins. In recent years this model has been further developed. In particular, it was used to calculate the circulation applying vortex capable [16] and large-eddy [17] approaches. 
A flexible hierarchical model, describing the large-scale circulation in the Black Sea basin is applied for numerical calculations in the present article. The hierarchical structure of the model is based on the method of multicomponent splitting. It includes a splitting both under physical processes and geometric coordinates [18]. The program features a modular principle: every single step of splitting is represented by a separate software module. As a result of splitting a complex system of equations of the sea dynamics is divided into a number of modules with a simpler structure.

Below we are to examine the principal equations of the sea dynamics within the framework of the approach proposed. The model refers to the class of sea environment $\sigma$-models. As the vertical coordinate the dimensionless variable $\sigma \in[0,1]$ is applied, preset in the case when the free surface of a fluid is taken in account by the following ratio

$$
\sigma=(z-\zeta) /(H-\zeta)
$$

where $z$ is the Cartesian vertical coordinate; $H$ is the depth of the ocean in a quiescent state, intended by the limited function with bounded derivatives; $\zeta$ is the sea level displacement from the undisturbed position.

Here is the statement of the problem of the ocean circulation simulation in the generalized coordinate frame. The transition from the Cartesian coordinate system to the generalized one is preset by the direct and inverse conversion differentials:

$$
\frac{D \mathbf{Y}}{D \mathbf{X}}=\left[\begin{array}{lll}
\partial x / \partial X_{1} & \partial x / \partial X_{2} & \partial x / \partial X_{3} \\
\partial y / \partial X_{1} & \partial y / \partial X_{2} & \partial y / \partial X_{3} \\
\partial z / \partial X_{1} & \partial z / \partial X_{2} & \partial z / \partial X_{3}
\end{array}\right], \frac{D \mathbf{X}}{D \mathbf{Y}}=\left[\begin{array}{lll}
\partial X_{1} / \partial x & \partial X_{1} / \partial y & \partial X_{1} / \partial z \\
\partial X_{2} / \partial x & \partial X_{2} / \partial y & \partial X_{2} / \partial z \\
\partial X_{3} / \partial x & \partial X_{3} / \partial y & \partial X_{3} / \partial z
\end{array}\right]
$$

where $\mathbf{X}=\left(X_{1}, X_{2}, X_{3}\right)$ - the Cartesian coordinates with an identity metrics matrix $G^{(\mathbf{X})}=\operatorname{diag}(1,1,1)$, and $\mathbf{Y}=(x, y, z)$ are the arbitrary generalized coordinates. At the same time at each space point it is possible to construct a system of local basis vectors $(\mathbf{i}, \mathbf{j}, \mathbf{k})=(\partial \mathbf{X} / \partial x, \partial \mathbf{X} / \partial y, \partial \mathbf{X} / \partial z)$, directed along the corresponding generalized coordinates. If $(D \mathbf{X} / D \mathbf{Y})^{T}(D \mathbf{X} / D \mathbf{Y})$ is a diagonal matrix, the system of local basis vectors $(\mathbf{i}, \mathbf{j}, \mathbf{k})$ is orthogonal. Then the coordinate system $\mathbf{Y}=(x, y, z)$ is called orthogonal and the metrics matrix for it is of the following form

$$
G^{(\mathbf{Y})}=(D \mathbf{X} / D \mathbf{Y})^{T} G^{(\mathbf{X})}(D \mathbf{X} / D \mathbf{Y})=\operatorname{diag}\left(r_{1}^{2}, r_{2}^{2}, r_{3}^{2}\right),
$$

and the metric coefficients $r_{i}$ can be calculated according to the following formula

$$
r_{i}=\left|\left(\frac{\partial X_{1}}{\partial i}, \frac{\partial X_{2}}{\partial i}, \frac{\partial X_{3}}{\partial i}\right)\right|(i=x, y, z) .
$$

The basis of mathematical ocean model is the system of primitive equations in the hydrostatic and Boussinesq approximations recorded in generalized orthogonal coordinates horizontally and $\sigma$-coordinate system vertically. The model equations are of the following form 


$$
\begin{gathered}
D_{t} u-(l+\xi) v H=-\frac{H}{r_{x}}\left(\frac{1}{\rho_{0}} P_{x}+\frac{1}{\rho_{0}} \frac{\partial p_{a}}{\partial x}+g \frac{\partial \zeta}{\partial x}\right)+\frac{\partial}{\partial \sigma} \frac{v}{H} \frac{\partial u}{\partial \sigma}+F v \\
D_{t} v+(l+\xi) u H=-\frac{H}{r_{y}}\left(\frac{1}{\rho_{0}} P_{y}+\frac{1}{\rho_{0}} \frac{\partial p_{a}}{\partial y}+g \frac{\partial \zeta}{\partial y}\right)+\frac{\partial}{\partial \sigma} \frac{v}{H} \frac{\partial v}{\partial \sigma}-F u \\
\frac{1}{r_{x} r_{y}}\left(\frac{\partial u H r_{y}}{\partial x}+\frac{\partial v H r_{x}}{\partial y}\right)+\frac{\partial \omega}{\partial \sigma}=\frac{\partial \zeta}{\partial t}, \\
D_{t} \theta=\frac{\partial}{\partial \sigma} \frac{v_{\theta}}{H} \frac{\partial \theta}{\partial \sigma}+D \theta+\frac{\partial R}{\partial \sigma} \\
D_{t} S=\frac{\partial}{\partial \sigma} \frac{v_{S}}{H} \frac{\partial S}{\partial \sigma}+D S, \\
\rho=\hat{\rho}\left(\theta, S+35 \%{ }_{00}, p_{w}\right)-\hat{\rho}\left(0,0, \rho_{0} g \sigma H\right) .
\end{gathered}
$$

Here $p_{a}$ - atmospheric pressure; $\mathbf{u}=(u, v)$ - horizontal velocity vector, $u$ and $v$ - its zonal and meridional projections; $\omega$ - vertical velocity in $\sigma$-coordinate system, connected with the vertical velocity $w$ in $z$-coordinate system by following ratio

$$
\omega=w-\left(\frac{u}{r_{x}} \frac{\partial Z}{\partial x}+\frac{v}{r_{y}} \frac{\partial Z}{\partial y}+\frac{\partial Z}{\partial t}\right) ;
$$

$\theta$ is the potential temperature; $R$ is the solar radiation penetrating flow; $S$ is the salinity excluding the $35 \%$ constant; $\rho$ is the deviation from the water density of mean density distribution depending only on the pressure of the liquid column $\rho_{0} g z$ under the mean density in the ocean $\rho_{0}=1.025 \Gamma^{\cdot} \mathrm{cm}^{-3}$ at the depth $z=\sigma H$; the Coriolis parameter $l=2 \widetilde{\Omega} \sin \phi$, where $\tilde{\Omega}=\frac{2 \pi}{86400}\left(1+\frac{1}{365 \cdot 24}\right) \mathrm{s}^{-1}$ is the Earth's angular velocity based on the annual rotation around the Sun, $\phi$ is the geographic latitude; $\xi=\frac{1}{r_{x} r_{y}}\left(\frac{\partial r_{y}}{\partial x} v-\frac{\partial r_{x}}{\partial y} u\right)$ is the summand describing the additional momentum transfer in curvilinear coordinates; $v$ and $v_{\theta}, v_{s}$ are the coefficients of vertical turbulent viscosity and diffusion coefficients of vertical turbulent heat and salt, respectively, that in the case of a stably stratified vertical profile of potential density are calculated according to the Pacanowski-Philander or Monin-Obukhov parameterization, and in the case of the unstable stratified one - are considered larger for convection parameterization. The nonlinear equation of state $\rho=\hat{\rho}\left(\theta, S+35 \%\right.$, $\left.p_{w}\right)$ to calculate the density of water, taking into account the compressibility due to the water column pressure is taken from [18].

The horizontal pressure gradient components $P_{x}$ and $P_{y}$ in the equations (5) and (6) are calculated using a hydrostatic equation in a special form: 


$$
\begin{gathered}
P_{x}=\frac{1}{2} g\left\{\frac{\partial}{\partial x}\left[H \int_{0}^{\sigma}\left(\rho-\sigma \frac{\partial \rho}{\partial \sigma}\right) d \sigma\right]-\sigma\left(\frac{\partial H}{\partial x} \rho-H \frac{\partial \rho}{\partial x}\right)\right\}, \\
P_{y}=\frac{1}{2} g\left\{\frac{\partial}{\partial y}\left[H \int_{0}^{\sigma}\left(\rho-\sigma \frac{\partial \rho}{\partial \sigma}\right) d \sigma\right]-\sigma\left(\frac{\partial H}{\partial y} \rho-H \frac{\partial \rho}{\partial y}\right)\right\},
\end{gathered}
$$

which can reduce errors in their difference approximations in $\sigma$-coordinate system. Since $P_{x}=P_{y}=0$, for the vertically linear density profile we have $\rho=$ const $\times \sigma H$. Using the equation of state in the form of (10) also allows to reduce these errors because that part of the non-linear depth density profile, which does not contribute to the horizontal pressure gradient is subtracted in advance.

Translation operator, being part of the total derivative of the velocity components in (5) and (6), is used in the semi-divergent symmetrized form:

$$
\begin{gathered}
D_{t} \varphi=\frac{1}{2}\left(h \frac{\partial \varphi}{\partial t}+\frac{\partial h \varphi}{\partial t}\right)+ \\
+\frac{1}{2 r_{x} r_{y}}\left[r_{y} H u \frac{\partial \varphi}{\partial x}+\frac{\partial}{\partial x}\left(r_{y} H u \varphi\right)+r_{x} H v \frac{\partial \varphi}{\partial y}+\frac{\partial}{\partial y}\left(r_{x} H v \varphi\right)\right]+ \\
+\frac{1}{2}\left(\omega \frac{\partial \varphi}{\partial \sigma}+\frac{\partial \omega \varphi}{\partial \sigma}\right)
\end{gathered}
$$

where $\varphi$ is the variable $u$ or the variable $v$.

In the new model version the translation operator, being part of the total derivative of the scalar fields in the equations (8) and (9) is used in the divergent form:

$$
D_{t} \varphi=\frac{\partial h \varphi}{\partial t}+\frac{1}{r_{x} r_{y}}\left[\frac{\partial}{\partial x}\left(r_{y} H u \varphi\right)+\frac{\partial}{\partial y}\left(r_{x} H v \varphi\right)\right]+\frac{\partial \omega \varphi}{\partial \sigma},
$$

where $\varphi$ is $\theta$ or $S$, and if necessary, any other scalar fields.

The lateral heat and salt diffusion operator $D$ is selected equal for salt $\theta$ and $S$ in (8) and (9) and is recorded in the universal form:

$$
\begin{aligned}
D \varphi & =\frac{1}{r_{x} r_{y}} \frac{\partial}{\partial x}\left[K^{x} H \frac{r_{y}}{r_{x}}\left(\frac{\partial \varphi}{\partial x}-\kappa_{x} \frac{\partial \varphi}{\partial \sigma}\right)\right]-\frac{1}{r_{x} r_{y}} \frac{\partial}{\partial \sigma}\left[K^{x} H \frac{r_{y}}{r_{x}} \kappa_{x}\left(\frac{\partial \varphi}{\partial x}-\kappa_{x} \frac{\partial \varphi}{\partial \sigma}\right)\right]+ \\
& +\frac{1}{r_{x} r_{y}} \frac{\partial}{\partial y}\left[K^{y} H \frac{r_{x}}{r_{y}}\left(\frac{\partial \varphi}{\partial y}-\kappa_{y} \frac{\partial \varphi}{\partial \sigma}\right)\right]-\frac{1}{r_{x} r_{y}} \frac{\partial}{\partial \sigma}\left[K^{y} H \frac{r_{x}}{r_{y}} \kappa_{y}\left(\frac{\partial \varphi}{\partial y}-\kappa_{y} \frac{\partial \varphi}{\partial \sigma}\right)\right]
\end{aligned}
$$

where $\varphi$ is either $\theta$, or $S$, and $K^{x}(x, y, \sigma H)$ and $K^{y}(x, y, \sigma H)$ are the $2^{\text {nd }}$ order horizontal diffusion coefficients with respect to $x$ and $y$, chosen as some functions of the spatial coordinates. The variables $\kappa_{x}$ and $\kappa_{y}$ preset one combination or the combination of several functions with the lateral diffusion going along their isosufaces. These particularly may be $\sigma$-, $Z$ - or $\rho$-surfaces. 
The lateral viscosity operator $F$ in the equations (5) and (6) is a combination of operators of the $2^{\text {nd }}$ and $4^{\text {th }}$ order:

$$
F \varphi=H \operatorname{div}_{h}\left(\operatorname{Agrad}_{h}\right) \varphi-H\left(\operatorname{div}_{h}\left(\mathbf{B}^{1 / 2} \operatorname{grad}_{h}\right)\right)^{2} \varphi,
$$

where $\varphi$ is either $u$, or $\operatorname{grad}_{h}$ and $\operatorname{div}_{h}$ - bivariate lateral gradient and divergence operators acting on the surfaces $\sigma=$ const. The values $\mathbf{A}$ and $\mathbf{B}$ are the diagonal $2^{\text {nd }}$ order tensors:

$$
\mathbf{A}=\left(\begin{array}{cc}
A^{x} & 0 \\
0 & A^{y}
\end{array}\right), \quad \mathbf{B}=\left(\begin{array}{cc}
B^{x} & 0 \\
0 & B^{y}
\end{array}\right),
$$

where $A^{x}=A^{x}(x, y), \quad A^{y}=A^{y}(x, y), \quad B^{x}=B^{x}(x, y), \quad B^{y}=B^{y}(x, y)$ are the viscosity coefficients for the $2^{\text {nd }}$ and $4^{\text {th }}$ order operators along $x$ and $y$, preset like some of the functions of the spatial coordinates. The $4^{\text {th }}$ order operator, as compared with the $2^{\text {nd }}$ order operator suppresses high spatial harmonics more effectively and less distorts the basic large scale solution.

Boundary conditions of the model. The momentum flux from the wind friction stress $\tau_{x}, \tau_{y}$ and universal condition for $\omega$ are preset as the boundary conditions for the velocity at the ocean surface $(\sigma=0)$ :

$$
-\left.\frac{v}{H} \frac{\partial \mathbf{u}}{\partial \sigma}\right|_{\sigma=0}=\frac{\left(\tau_{x}, \tau_{y}\right)}{\rho_{0}},\left.\omega\right|_{\sigma=0}=0,
$$

and for the temperature and salinity - normalized flows of the heat $q_{\theta}$ and salt $q_{S}$ :

$$
-\left.\frac{v_{\theta}}{H} \frac{\partial \theta}{\partial \sigma}\right|_{\sigma=0}=q_{\theta}, \quad-\left.\frac{v_{S}}{H} \frac{\partial S}{\partial \sigma}\right|_{\sigma=0}=q_{S} .
$$

The flow $q_{\theta}$ is calculated taking in account the flow of sensible and latent heat, long wave and short-wave radiation and the flow caused by the presence of ice, and the flow $q_{S}$ - taking into account the balance of fresh water due to precipitation, evaporation, river flow and the formation or melting of ice.

At the bottom ( $\sigma=1)$ the impermeability conditions have quite a simple form in $\sigma$-coordinate system

$$
\left.\omega\right|_{\sigma=0}=0,
$$

and the condition of the quadratic bottom friction

$$
-\left.\frac{v}{H} \frac{\partial \mathbf{u}}{\partial \sigma}\right|_{\sigma=0}=\left.C_{D} \sqrt{u^{2}+v^{2}+e_{b}^{2}} \mathbf{u}\right|_{\sigma=1},
$$

where $C_{D}=2.5 \cdot 10^{-3}$ and $e_{b}=5 \mathrm{~cm} \cdot \mathrm{s}^{-1}$ are empirical constants.

The impermeability and free gliding conditions are preset for the velocity on the lateral surface. On the solid areas of the lateral boundary and at the bottom the isolation conditions are specified for temperature and salinity. If the basin is not barred, temperature and salinity values taken from observations are preset at the liquid parts of the lateral boundary.

In $\sigma$-ocean circulation model can be incorporated model of the sea ice dynamics - thermodynamics [19]. 
Peculiarities of the INM RAS circulation $\sigma$-model numerical implementation. The main feature of this model, which distinguishes it from the known ocean models, is that under the numerical implementation it uses the splitting method [20] on the physical processes and spatial coordinates.

For this purpose, the ocean thermohydrodynamics equations are written in a special symmetrized form. It allows the operator to introduce a differential problem in the form of a sum of simpler operators. Each operator is non-negative according to the norm defined by the law of conservation of total energy. This permits to split the complete problem operator into several operators of simpler problems [20] and to build the spatial approximation of the corresponding groups of summands (in different equations), so that the law of conservation of energy, carried out for the original differential problem, satisfies all split discrete tasks. Finite-difference approximations of the equations are based on the $C$ grid.

The splitting method can effectively realize the implicit time integration schemes for the transport-diffusion equations. The problem of geostrophic adjustment components of the Coriolis acceleration were implicitly approximated.

Module structure of the model. Before the solution of the equations (5) (10) in the model the following subsidiary calculations are performed. Their results are used in solving the basic system of equations.

The initial atmospheric data are set in the normal geographic coordinate system with the spatial and temporal resolution, different from the model, so they are transferred to a model domain in the calculation model block by spatial and temporal interpolation.

Calculation of sea ice characteristics is based on locally one-dimensional model of thermodynamics [19], the transport model [21] and the model of the ice dynamics [22].

Calculation of heat, salt and pulse flows to the ocean is carried out applying both model domain interpolated atmospheric data and calculated sea ice characteristics, as well as the ocean surface characteristics from the solution of the problem at this point in time, considered to be known.

The splitting of the system of equations (5) - (9) is carried out at several hierarchical levels. At first the splitting into physical processes is performed. At higher levels, the splitting process comes to selection of the simplest space locally one-dimensional equations. At each time integration interval $\left(t_{j}, t_{j+1}\right]$ the process described by the partly linearized system of equations (5) - (9), is represented as a superposition of the transport-diffusion process for $\theta, S, u, v$ and the process of adaptation of the velocity and density fields. In differential formulation these problems are described by the following equations (solution of the original problem at a point in time $t_{j}$ considered to be known):

of transport - diffusion $\theta$ and $S$ -

$$
D_{t} \theta=\frac{\partial}{\partial \sigma} \frac{v_{\theta}}{H} \frac{\partial \theta}{\partial \sigma}+D \theta+\frac{\partial R}{\partial \sigma}, \quad D_{t} S=\frac{\partial}{\partial \sigma} \frac{v_{S}}{H} \frac{\partial S}{\partial \sigma}+D S ;
$$

of transport - diffusion $u$ and $v-$

$$
D_{t} u-\xi v H=\frac{\partial}{\partial \sigma} \frac{v}{H} \frac{\partial u}{\partial \sigma}+F u, \quad D_{t} v-\xi u H=\frac{\partial}{\partial \sigma} \frac{v}{H} \frac{\partial v}{\partial \sigma}+F v .
$$


The process of adaptation of the hydrological fields is described by a system of three equations:

$$
\begin{gathered}
\frac{\partial u}{\partial t}-l v=-\frac{1}{r_{x}}\left(\rho_{0} P_{x}+\frac{1}{\rho_{0}} \frac{\partial p_{a}}{\partial x}-g \frac{\partial \zeta}{\partial x}\right), \\
\frac{\partial v}{\partial t}+l u=-\frac{1}{r_{y}}\left(\rho_{0} P_{y}+\frac{1}{\rho_{0}} \frac{\partial p_{a}}{\partial y}-g \frac{\partial \zeta}{\partial y}\right), \\
\frac{\partial \zeta}{\partial t}=\frac{1}{r_{x} r_{y}}\left(\frac{\partial r_{y} u H}{\partial x}+\frac{\partial r_{x} v H}{\partial y}\right)+\frac{\partial \omega}{\partial \sigma} .
\end{gathered}
$$

The transport - diffusion process is implemented by splitting according to the physical processes: transport, lateral diffusion and vertical diffusion. To solve the time transport problem the Adams - Bashforth explicit method is applied. Divergent form of the transport operator provides the maintaining of heat and salt in the ocean in case when there are no flows in the boundaries. Time problem for the lateral diffusion is solved under the explicit difference scheme and the vertical - under the implicit one.

To describe the transport - diffusion process the splitting according to the elementary transport - diffusion along the coordinates is applied. This operation is allowed by the semi-divergent form, possessing on the assumption of impermeability at the boundaries a property of skew-symmetry (non-negativeness) for each direction separately.

The process of adaptation of the hydrological fields is achieved in two stages. At first, according to the values $\theta$ and $S$, obtained in the first stage, the density and further on the equation the pressure gradient components $P_{x}$ and $P_{y}$ are calculated (11). According to the calculated $P_{x}$ and $P_{y}$ the stipulated pulse change is computed:

$$
\frac{\partial u}{\partial t}=-\frac{1}{\rho_{0} r_{x}} P_{x}, \quad \frac{\partial v}{\partial t}=-\frac{1}{\rho_{0} r_{y}} P_{y} .
$$

The rest of the system is solved by separation into barotropic and baroclinic modes:

$$
u=\bar{u}+u^{\prime}, \quad v=\bar{v}+v^{\prime}, \quad \bar{u}=\int_{0}^{1} u d \sigma, \quad \bar{v}=\int_{0}^{1} v d \sigma .
$$

This leads to the division of the equations into two systems of equations describing the adaptation of baroclinic and barotropic modes.

The system of baroclinic adaptation equations has the following form

$$
\frac{\partial u^{\prime}}{\partial t}-l v^{\prime}=0, \quad \frac{\partial v^{\prime}}{\partial t}+l u^{\prime}=0 \text {. }
$$

The implicit scheme with the methodology of the spatial operator diagonalization for the Coriolis members applying $C$ grids is used in solution of this system. 
The vertical velocity is obtained by depth integrating the continuity equations (7) according to the calculated horizontal components of the baroclinic velocity taking into the account the conditions of impermeability and free glide on the lateral boundaries:

$$
\omega=\int_{1}^{\sigma} \frac{1}{r_{x} r_{y}}\left(\frac{\partial u^{\prime} H r_{y}}{\partial x}+\frac{\partial v^{\prime} H r_{x}}{\partial y}\right) d \sigma .
$$

Boundary conditions for the vertical velocity on the surface and at the bottom are satisfied automatically because $\int_{0}^{1} u^{\prime} d \sigma=\int_{0}^{1} v^{\prime} d \sigma=0$.

Implementation of the barotropic adaptation process requires a joint solution of three equations written applying an implicit time scheme:

$$
\begin{aligned}
& \frac{\partial \bar{u}}{\partial t}-l \bar{v}=\frac{1}{r_{x}}\left(g \frac{\partial \zeta}{\partial x}-\frac{1}{\rho_{0}} \frac{\partial p_{a}}{\partial x}\right), \\
& \frac{\partial \bar{v}}{\partial t}+l \bar{u}=\frac{1}{r_{y}}\left(g \frac{\partial \zeta}{\partial y}-\frac{1}{\rho_{0}} \frac{\partial p_{a}}{\partial y}\right), \\
& \frac{\partial \zeta}{\partial t}=\frac{1}{r_{x} r_{y}}\left(\frac{\partial r_{y} \bar{u} H}{\partial x}+\frac{\partial r_{x} \bar{v} H}{\partial y}\right) .
\end{aligned}
$$

This problem can be solved by both direct and iterative methods.

Implementation of $\sigma$-model for the Black Sea circulation description. The considered $\sigma$-model version with the splitting procedure covers the Black Sea water area. It allows registration of the Azov Sea. Estimated area is located from the $27^{\circ} 26^{\prime} 60$ " to $41^{\circ} 45^{\prime} 00^{\prime \prime} \mathrm{E}$ and from $40^{\circ} 54^{\prime} 36^{\prime \prime}$ to $47^{\circ} 16^{\prime} 12^{\prime \prime} \mathrm{N}$ with a spatial resolution $\left(0^{\circ} 3^{\prime}\right) \times\left(0^{\circ} 2^{\prime} 24 "\right)$ in longitude and latitude, respectively. The grid domain in the horizontal plane comprises $287 \times 160$ knots. Vertically there are preset $40 \sigma$-levels unevenly distributed in the depth. The time step on the basis of the solution stability conditions is $300 \mathrm{~s}$.

Bottom bathymetry was obtained according to the data of Sevastopol branch of Zubov State Oceanographic Institute (ZSOI), which are represented in the form of separate topography maps of the Black Sea water area with a resolution of $\left(0^{\circ} 0^{\prime} 36,00^{\prime \prime}\right) \times\left(0^{\circ} 0^{\prime} 36,00^{\prime \prime}\right)$ in longitude and latitude and the ones of the Azov Sea with the spatial resolution, $\left(0^{\circ} 0^{\prime} 35,06^{\prime \prime}\right) \times\left(0^{\circ} 0^{\prime} 35,06^{\prime \prime}\right)$ respectively. Initial highresolution data are smoothed to eliminate local peculiarities, and then interpolated on the modeling domain. Further the model bathymetry on the grid with a resolution $\left(0^{\circ} 3^{\prime}\right) \times\left(0^{\circ} 2^{\prime} 24 "\right)$ on the latitude and longitude was smoothed again to eliminate knees. The lateral boundaries of the domain are given in the form of a vertical wall with a minimum depth of $5 \mathrm{~m}$. The topography smoothing and a nonzero depth at all points in the domain, including onshore, are necessary for the ocean $\sigma$-model, as it uses the vertical coordinate transformation (1). The basin bathymetry is shown in Fig. 3. 


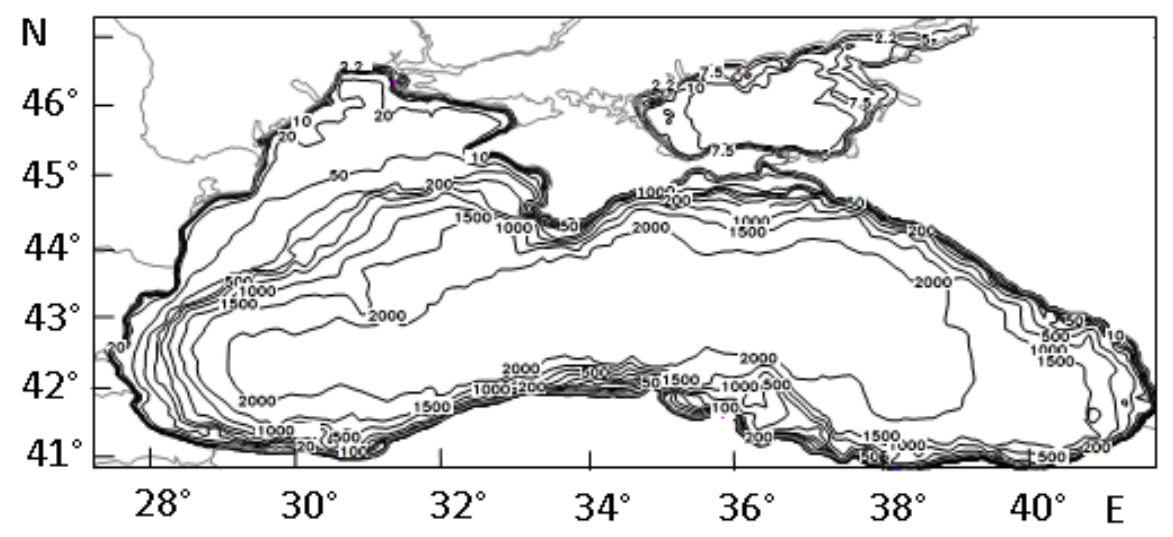

Fig. 3. The Black Sea bathymetry (m)

To set the initial conditions on the ocean surface, as well as for the construction of the initial data depth distributions, the materials provided by the Sevastopol branch of ZSOI were used. They contain data of monthly climatic temperature and salinity fields of the Black Sea. The initial temperature and salinity fields, as well as monthly ones on the surface of the Black Sea were calculated on the basis of the provided data.

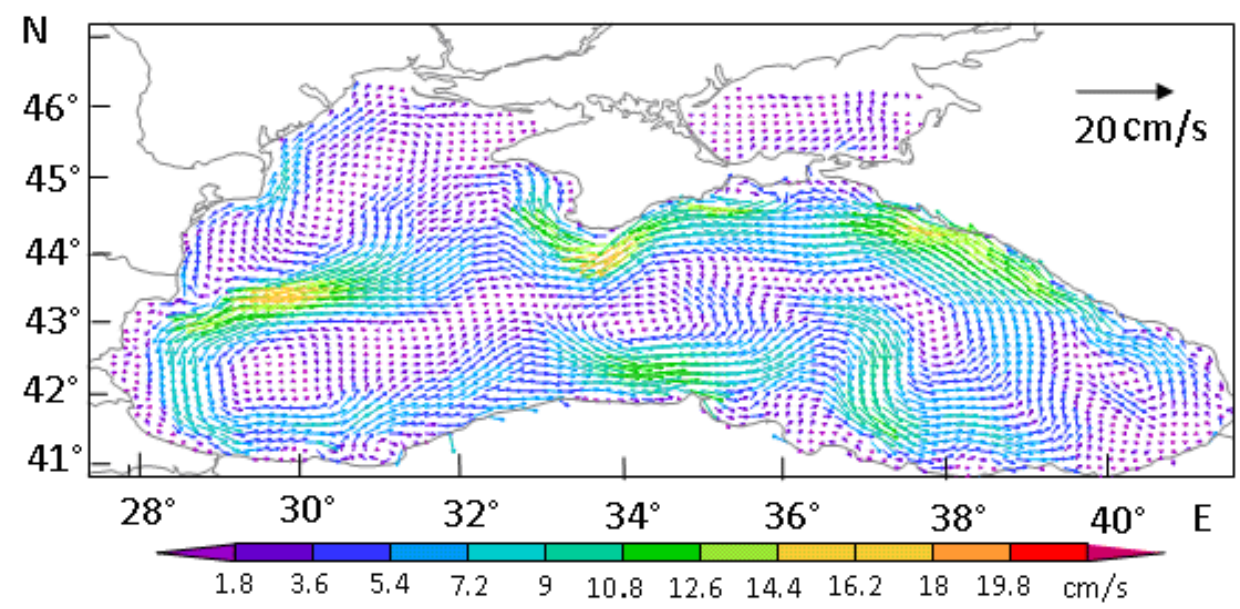

Puc. 4. Field of the Black Sea currents on the $10 \mathrm{~m}$ depth, calculated for October, 7, 2007 (arrows are shown for each of the third point of the computational grid)

Since we are dealing with the general circulation ocean model, which uses a $\sigma$-coordinate system, there is a need for interpolation of 3-dimensional data fields. Transferring to the model, the data are moved to $\sigma$-levels. Note, that the $\sigma$-coordinates $(\sigma=z / H)$ is a coordinate system where the sea surface is taken as a zero depth, and the bottom $(-H)$ corresponds to the maximum depth (at each point) with the coordinate value equal to one. Levels in such a coordinate system

PHYSICAL OCEANOGRAPHY NO. 1 (2016) 
do not coincide with the standard horizons, where the initial grid temperature and salinity data are usually located. Scaling to $\sigma$-levels is carried out as follows. At first, a two-dimensional interpolation is performed on the model grid by the algorithm described above. Then vertically a piecewise-linear data representation is used, which is followed by the calculation of the desired depths by means of a simple procedure of one-dimensional linear interpolation.
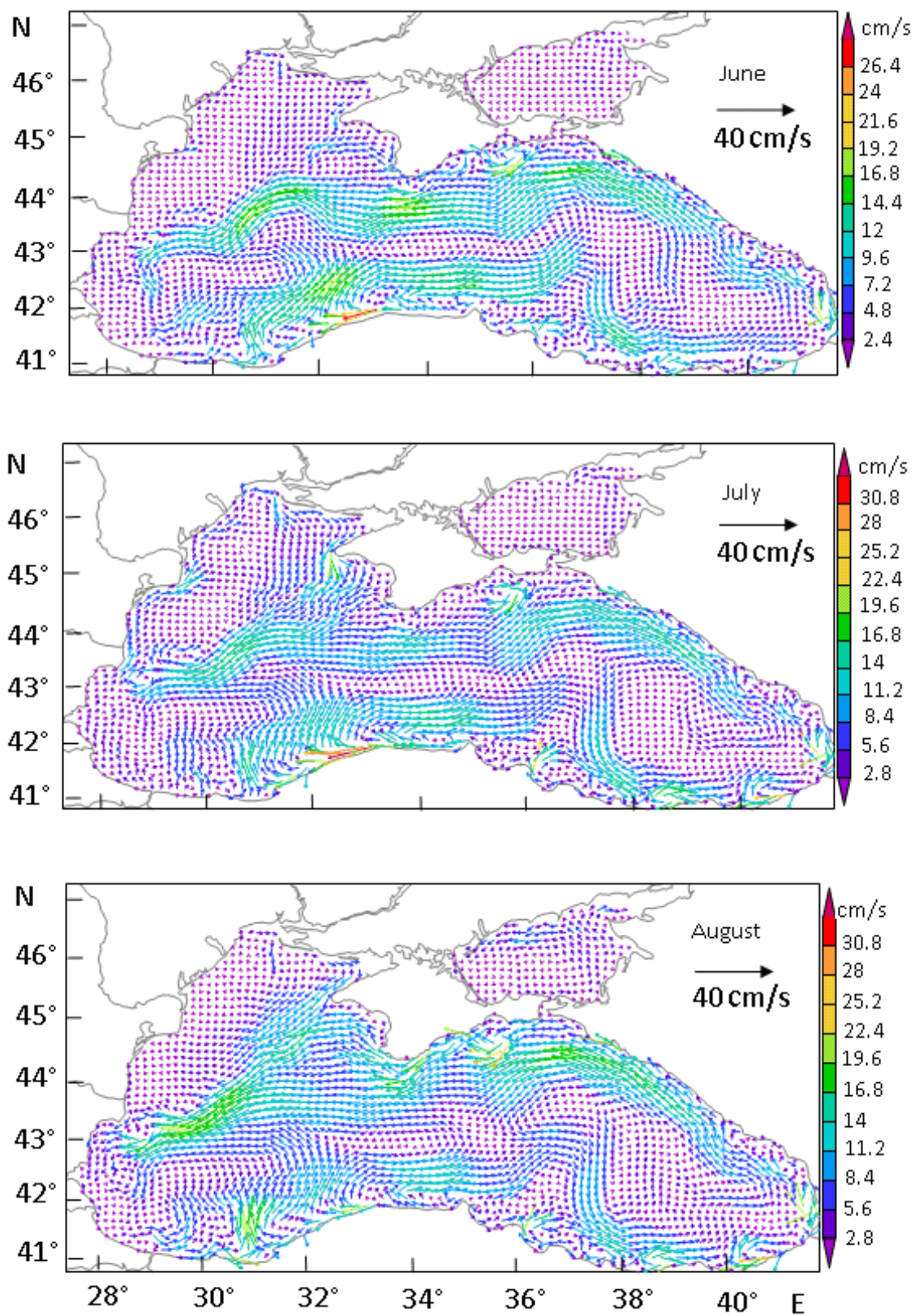

Fig. 5. The average monthly Black and Azov Sea circulation at a depth of $5 \mathrm{~m}$ in June, July and August 2007 (arrows are shown for each of the third point of the computational grid) 
Below see the examples of numerical experiments of the calculation of the Black and Azov Sea circulation. To verify the model, a series of numerical experiments was carried out for the period from 1 January 2007 to 31 December 2008 applying various model parameters. As weather impact characteristics ERAInterim reanalysis data were used.

It turned out that the results of calculations, especially the reproduction of the cold intermediate layer in the temperature field, essentially depends on the coefficients of viscosity and diffusion of both horizontal and vertical. After a series of experiments, the following parameters were selected: binding to the surface temperature of -0.0 ; binding to the surface salinity $-2.0 \cdot 10^{-3} \mathrm{~cm} \cdot \mathrm{s}^{-1}$; the $2^{\text {nd }}$ order horizontal diffusion coefficient $-5.0 \cdot 10^{5} \mathrm{~cm}^{2} \cdot \mathrm{s}^{-1}$; the $4^{\text {th }}$ order lateral viscosity coefficient $-41.0 \cdot 10^{17} \mathrm{~cm}^{4} \cdot \mathrm{s}^{-1}$.

The Pacanowski-Philander vertical parameterization was applied: the vertical diffusion coefficient for temperature $-0.5-0.0005 \mathrm{~cm}^{2} \cdot \mathrm{s}^{-1}$; the vertical diffusion coefficient for salinity $-0.1-0.0001 \mathrm{~cm}^{2} \cdot \mathrm{s}^{-1}$; the vertical viscosity coefficient $10.0-1.0 \mathrm{~cm}^{2} \cdot \mathrm{s}^{-1}$.

Fig. 4 demonstrates the field of the Black Sea currents on the $10 \mathrm{~m}$ depth, calculated for October, 7, 2007 by the method described above. The Black Sea Rim Current is well-marked. The Black Sea circulation vortex structure is understated due to the high $2^{\text {nd }}$ order viscosity coefficient in this experiment $\left(10^{6} \mathrm{~cm}^{2} \cdot \mathrm{s}^{-1}\right)$.

Fig. 5 shows the change in average monthly circulation at a depth of $5 \mathrm{~m}$ in June, July and August 2007.

According to the results of calculations quite strong volatility level variations during the year can be traced, the Knipovich glasses are seen. Batumi anticyclone is not clearly reproduced, due to the rough set of the atmospheric forcing spatial distribution according to ERA-Interim reanalysis data

Adding to the model the tide-generating potential block. In general, the current global tide models can be divided into three groups: the hydrodynamic, empirical and hydrodynamic with monitoring data assimilation (mareographs and satellite altimetry) $[14,23,24]$. Forecast of tides in the Black Sea applying the latter two types of models appears to be complicated due to the lack of continuous series of observations. Existing data is scattered, that does not allow performing the data interpolation between the calibration stations and obtaining a picture of tidal constituents.

To describe the generation of the tides three main approaches are applied: in the equation to the tide-generating potential is added [25]; the special boundary condition simulating the entrance of tidal waves in the computational domain is preset in the open boundaries [26, 27]; two approaches are simultaneously applied [28 - 31]. The Black Sea is an inland sea of the Atlantic Ocean. The Bosporus connects it to the Sea of Marmara, through the Dardanelles it is connected with the Aegean and Mediterranean Seas, and through the Kerch Strait - with the Azov Sea. The Mediterranean tides are attenuated in the straits, so the tides in the Black Sea are formed only under the influence of tide-generating forces. For a description of PHYSICAL OCEANOGRAPHY NO. 1(2016) 
the tide generation we recommend to apply the approach that involves the addition to the initial system of primitive equations (5) - (9) in the hydrostatic and Boussinesq approximations recorded in horizontally generalized orthogonal coordinates and vertically in coordinate $\sigma$-system, the $\Omega_{M}$ Moon tide-generating potential or/and $\Omega_{S}$ Sun tide-generating potential, defined in the following way

$$
\Omega_{M}=\frac{3 r_{e}^{2}}{2 l_{M}^{3}} G M_{M}\left(\cos ^{2} Z_{M}-\frac{1}{3}\right), \Omega_{S}=\frac{3 r_{e}^{2}}{2 l_{S}^{3}} G M_{S}\left(\cos ^{2} Z_{S}-\frac{1}{3}\right),
$$

where $G$ - gravitation constant, $M_{M}$ and $M_{S}$ - masses of the Moon and Sun, $r_{e}$ radius of the Earth, $l_{M}$ and $l_{S}$ - distance from the center of the Earth to the Moon and the Sun centers, $Z_{M}$ and $Z_{S}$ - zenith angles of the Sun and Moon.

Zenith angle is expressed through the $\delta$ declination (of the Moon, the Sun), $\Phi$ latitude of the observer and $\alpha$ hour angle (the angular distance along the celestial equator from the observer's meridian to the meridian of a celestial body) according to the formula $\cos Z=\cos \delta \cos \Phi \cos \alpha+\sin \delta \sin \Phi$. The hour angle is calculated as follows: $\alpha=\lambda+360^{\circ} t / T$, where $\lambda$ - the longitude of the observer, $T$ - the period a celestial body is returned within to the observer's meridian [25, 29, 32].

All of the aforementioned variables should be known at each estimated time point. Their values were obtained using a special functional US Naval Observatory $[33,34]$ and prepared in a form of an array as the initial data.

Hence, the equations (5), (6) of described above the Black and Azov Sea joint circulation $\sigma$-model take the following form:

$$
\begin{aligned}
& D_{t} u-(l+\xi) v H=-\frac{H}{r_{x}}\left(\frac{1}{\rho_{0}} P_{x}+\frac{1}{\rho_{0}} \frac{\partial p_{a}}{\partial x}+g \frac{\partial \zeta}{\partial x}\right)+\frac{\partial}{\partial \sigma} \frac{v}{H} \frac{\partial u}{\partial \sigma}+F v-\frac{\partial \Omega_{T}}{\partial x}, \\
& D_{t} v+(l+\xi) u H=-\frac{H}{r_{y}}\left(\frac{1}{\rho_{0}} P_{y}+\frac{1}{\rho_{0}} \frac{\partial p_{a}}{\partial y}+g \frac{\partial \zeta}{\partial y}\right)+\frac{\partial}{\partial \sigma} \frac{v}{H} \frac{\partial v}{\partial \sigma}-F u-\frac{\partial \Omega_{T}}{\partial y}
\end{aligned}
$$

where $\Omega_{T}$ - gravitation potential of the Moon $\left(\Omega_{M}\right)$ and the Sun $\left(\Omega_{S}\right)$ or their sum $\left(\Omega_{M}+\Omega_{S}\right)$. Unlike the initial equations, they are adapted to calculate the tides.

Conclusion. Hence, the literature data on the tide fluctuations of hydrophysical fields in the Black Sea were generalized. The analysis of tide parameters in the Black Sea based on the field data for the various marine coastal areas. The characteristics of the basic parameters of tide oscillations in the region are presented, and the examples of cotidal map and isoamplitude semi-diurnal tide maps are given.

The $\sigma$-model of the ocean circulation developed in the Institute of Numerical Mathematics of RAS was applied. The model spatial resolution over the longitude and latitude was about $4 \mathrm{~km}$. 40 irregularly distributed $\sigma$-levels were preset over the vertical; the step in time to provide the solution stability was $300 \mathrm{~s}$. 
Analysis of the results showed that the vortex structure is distinctly manifested in the Black Sea circulation. The Rim Current which characterizes general cyclonic circulation along the Black Sea perimeter forming two evident vortices is reproduced. In general, the numerical modeling results showed a good match to the observation data, as well as the results of other models of the Black Sea.

Analysis of existing models describing tide oscillations permit to select the most appropriate approach to the modeling of tides and associated currents in the Black Sea basin. To describe generation of tides, the module corresponding to the Sun and Moon tide-generating potentials is introduced into the $\sigma$-model. The necessary expressions to determine tide-generating potentials of the Moon and the Sun were obtained.

Aknowledgements. The works on this subject were carried out under Russian Foundation for Basic Research financial support within the framework of the research project No. 14-45-01025 "r_yug_a".

\section{REFERENCES}

1. Kagan, B.A., 1968, "Gidrodinamicheskie modeli prilivnykh dvizheniy $v$ more [The hydrodynamic models of tidal movements in the sea]”, Leningrad, Gidrometeoizdat, 219 p. (in Russian).

2. Marchuk, G.I., Kagan, B.A., 1991, Dinamika okeanskikh prilivov [Dynamics of the ocean tides], Leningrad, Gidrometeoizdat, 471 p. (in Russian).

3. Androsov, A.A., Vol'tsinger, N.E., 2005, "Prolivy Mirovogo okeana. Obshchiy podkhod k modelirovaniyu [Straits of the World Ocean. The general approach to modeling]”, Moscow, Nauka, 2005, 187 p. (in Russian).

4. Goryachkin, Yu.N., Ivanov, V.A., 2006, “Uroven' Chernogo morya: proshloe, nastoyashchee i budushchee [The level of the Black Sea: past, present and future], Sevastopol, MGI NAN Ukrainy, 210 p. (in Russian).

5. Dotsenko, S.F., Ivanov, V.A., 2010, "Prirodnye katastrofy Azovo-Chernomorskogo regiona [Natural disasters of the Azov-Black Sea region], Sevastopol, ECOSI-Gidrofizika, 174 p. (in Russian).

6. Marinescu, A., Sclarin, O., 1968, “O. Les variations periodignes du nivean de la Mer Noire a longstanga”, Trans. Museum histoire nature Gr. Antipa, no. 1, pp. 531-535.

7. Endros, A., 1932, "Die Seiches des Schwarzen und Azowschen meers und die dortigen Hubhohen der Gezeiten”, Ann. Hyd. Mar.Met., Bd. 60, Ht. 11, s. 442-453.

8. Ivanov, V.A., Manilyuk, Yu.V. \& Cherkesov, L.V., 1996, “O seyshakh Chernogo morya [On the Black Sea seiches], Meteorologiya i gidrologiya, no. 11, pp. 57-63 (in Russian).

9. Arkhipkin, V.S., Ivanov, V.A. \& Nikolaenko, E.G., 1987, Modelirovanie sobstvennykh kolebaniy $v$ yuzhnykh moryakh [Simulation of the natural oscillations in the southern seas], Chislennoe Modelirovanie Gidrofizicheskikh Protsessov i Yavleniy $v$ Zamknutykh Vodoemakh, edited by A.S. Sarkisyan, Moscow, Nauka, pp. 78-91 (in Russian).

10. Goryachkin, Yu.N., Ivanov, V.A. \& Repetin, L.N. [et al.], 2002, "Seyshi v Sevastopol'skoy bukhte [Seiches in the Sevastopol Bay]”, Tr. UkrNIGMI, iss. 250, pp. 342-353 (in Russian).

11. Defant, A., 1961, “Physical Oceanography. V. 2”, Oxford, New York, Pergamon Press, 598 p. 
12. Yastreb, Ya.P., Khmara, T.V., 2005, "Sravnitel'naya kharakteristika prilivnykh volnovykh dvizheniy $v$ moryakh sredizemnomorskogo tipa [Comparative characteristics of the tidal wave motions in the seas of the Mediterranean type]”, Ekologicheskaya Bezopasnost' Pribrezhnoy i Shel'fovoy Zon i Kompleksnoe Ispol'zovanie Resursov Shel'fa, iss.12, pp. 60-69 (in Russian).

13. Yuce, H., 1993, “Analysis of the water level variations in the eastern Black Sea”, J. Coast. Res., vol. 9, no. 4, pp. 1075-1082.

14. Boon, J., 2004, "Secrets of the tide: tide and tidal current analysis and applications, storm surges and sea level trends", Woodhead Publishing, 224 p.

15. Le Provost, C.F., Lyard, F. \& Molines, J.M. [et al.], 1998, “A hydrodynamic ocean tide model improved by assimilating a satellite altimeter-derived data set”, J. Geophys. Res., vol. 103, no. C3, pp. 5513-5529.

16. Moshonkin, S.N., Dianskiy, N.A. \& Gusev, A.V., 2007, "Vliyanie vzaimodeystviya Atlantiki s Severnym Ledovitym okeanom na Gol'fstrim [Influence of the Atlantic and Arctic Ocean ineratction with the Gulf Stream]”, Okeanologiya, vol. 47, no. 2, pp. 197-210 (in Russian).

17. Dianskiy, N.A., Zalesny, V.B. \& Moshonkin, S.N. [et al.], 2006, “Modelirovanie mussonnoy tsirkulyatsii Indiyskogo okeana s vysokim prostranstvennym razresheniem [The Indian Ocean monsoon circulation simulation with high spatial resolution]”, Okeanologiya, vol. 46, no. 4, pp. 421-442 (in Russian).

18. Marchuk, G.I., Rusakov, A.S. \& Zalesny, V.B. [et al.], 2005, "Splitting numerical technique with application to the high resolution simulation of the Indian Ocean circulation”, Pure Appl. Geophys., vol. 162, pp. 1407-1429.

19. Parkinson, C.L., Washington, W.M., 1979, “A large scale numerical model of sea ice”, $J$. Geophys. Res., vol. 84, no. C1, pp. 311-337.

20. Yakovlev, N.G., 2009, "Vosproizvedenie krupnomasshtabnogo sostoyaniya vod i morskogo l'da Severnogo Ledovitogo okeana v 1948-2002 gg. Chast' I. Chislennaya model' i srednee sostoyanie [Simulation of the large-scale condition of waters and sea ice of the Arctic Ocean in 1948-2002. Part I. A numerical model and the average]”, Izv. RAN. Fizika atmosfery $i$ okeana, vol. 45, no. 3, pp. 383-398 (in Russian).

21. Marchuk, G.I., 2009, “Metody vychislitel'noj matematiki [Computational mathematics methods]”, Saint Petersburg, Lan', 608 p. (in Russian).

22. Briegleb, B.P., Hunke, E.C. \& Bitz, C.M. [et al.], 2004, "The sea ice simulation of the Community Climate System Model”, version two, NCAR Tech. Note NCAR/TN-45+STR, $34 \mathrm{p}$.

23. Hunke, E.C., Dukowicz, J.K., 1997, “An elastic-viscous-plastic model for sea ice dynamics” J. Phys. Oceanogr., vol. 27, no. 9, pp. 1849-1867.

24. Arabelos, D.N., Papazachariou, D.Z. \& Contadakis, M.E. [et al.], 2011, “A new tide model for Mediterranean Sea based on altimetry and tide gauge assimilation”, Ocean Sci., vol. 7, no. 3, pp. 429-444.

25. Tierney, C.C., Kantha, L.H. \& Born, G.H., 2000, "Shallow and deep water global ocean tides from altimetry and numerical modeling”, J. Geophys. Res., vol. 105, no. C5, pp. 1125911277.

26. Feistel, R., Nausch, G. \& Wasmund, N., 2008, "State and evolution of the Baltic Sea, 19522005: a detailed 50-year survey of meteorology and climate, physics, chemistry, biology, and marine environment”, Hoboken, John Wiley \& Sons, 703 p.

27. Mzadek, R., 2005, "Hydrodynamic tidal model of Cook Strait”, Ecole MATMECA, 30 p.

28. Kowalik, Z., Untersteiner, N., 1978, “A study of the $\mathrm{M}_{2}$ tide in the Arctic Ocean”, Dt. Hydrogr. Z., vol. 31, s. 216-229. 
29. Tsimplis, M.N., Proctor, R. \& Flather, R.A., 1995, “A two dimensional tidal model for Mediterranean Sea”, J. Geophys. Res., vol. 100, no. C8, pp. 16223-16239.

30. Einšpigel, D., 2012, “Barotropní oceánický slapový model”, Univerzita Karlova v Praze, $55 \mathrm{p}$.

31. Luettich, R.A., Westerink, Jr. \& Westerink, J.J., 1995, “Continental shelf scale convergence studies with a barotropic tidal model. Quantitative skill assessment for Coastal Ocean Models”, Amer. Geophys. Union press., vol. 48, pp. 349-371.

32. Kowalik, Z., Proshutinsky, A.Y., 1993, “Diurnal tides in the Arctic Ocean”, J. Geophys. Res., vol. 98, no. C9, pp. 16449-16468.

33. Kowalik, Z., Luick, J., 2013, “The Oceanography of Tides”, Fairbanks, 157 p.

34. Kaplan, G., Bangert, J. [et al.], 2009, “User’s Guide to NOVAS 3.0”, Washington, U.S. Naval Observatory, 2009, $124 \mathrm{p}$. 